\title{
La ePIDEMia de VIH en Pueblos originarios DE MÉXico: PANORAMA NACIONAL Y UN ESTUdio de Caso etnográfico en los Altos de Chiapas
}

\author{
The HIV Epidemic Within Indigenous PeOples of \\ MeXico: National Overview \\ and an EThnographic Case Study \\ in The Highlands OF Chiapas
}

\section{Rubén Muñoz ${ }^{*}$ Patricia Ponce ${ }^{* *}$ Matías Stival $^{* \star *}$, Daniel Bernal ${ }^{* * * *}$}

Resumen: El presente artículo es fruto de los resultados de un estudio de revisión y análisis de los materiales publicados en América Latina y en México respecto a la prevención-atención y seguimiento oportuno de VIH en población indígena, y de una investigación etnográfica, en este contexto, en Los Altos de Chiapas. Tiene dos objetivos: en primer lugar, abordamos el estado de la cuestión de la prevalencia e incidencia de VIH en población indígena en México y algunas de las principales

\footnotetext{
"Doctor, profesor-investigador Conacyt en el Centro de Investigaciones y Estudios Superiores en Antropología Social, Unidad Sureste, San Cristóbal de Las Casas, Chiapas, México.

Correo e.: rubmuma@hotmail.com

** Doctora, profesora-investigadora del Centro de Investigaciones y Estudios Superiores en Antropología Social, Unidad Golfo, Xalapa, Veracruz, México.

Correo e.: pattyponce@gmail.com

${ }^{* * *}$ Licenciado, profesor de la Escuela de Antropología Nacional de Rosario, Argentina, e investigador del Programa de Antropología y Salud, Universidad de Buenos Aires, Argentina. Correo e.: matiasstival@yahoo.com.ar

${ }^{* * * *}$ MD-MCS, director médico e investigador del Centro de Atención al VIH, Casa Vida A.C.I Clínica Integral Almas, A.C., Álamos, Sonora, México.

Correo e.: drbernaljs5@gmail.com

Fecha de recepción: 1007 17; Fecha de aceptación: 140518.
}

(cc) EY-NC-ND Páginas 155-188. 
problemáticas en el acceso a las pruebas de detección y a la información que se provee en las instituciones de salud sobre VIH. En segundo lugar, discutimos las principales ausencias y omisiones desde la investigación académica, las políticas públicas y el nivel asociativo respecto al conocimiento e intervención en esta realidad que afecta a la población indígena del país, mediante algunas preguntas y recomendaciones de tipo teórico y práctico.

Palabras clave: VIH, sida, población indígena, políticas públicas, racismo.

Abstract: This article is the result of a review and analysis of the scientific publications in Latin America and in Mexico concerning the HIV prevention and health care for indigenous population, and an ethnographic research carried out in this thematic framework and population in the highlands of Chiapas. Two are the aims: First, we discuss the state of the art of the prevalence and incidence of HIV among indigenous population in Mexico and some of the main problems regarding the access to HIV testing and the information provided at the health care institutions about the infection. Secondly, we discuss the main absences and omissions within the academic research, the public policies, and the civil society activities concerning to the knowledge and intervention in this reality affecting the indigenous population across the country. We conclude by making some questions and providing certain theoretical and applied recommendations.

Keywords: HIV, aids, indigenous population, public policies, racism. 


\section{Introducción}

En el presente artículo abordamos el panorama de la prevalencia e incidencia de VIH en población indígena en México, exponemos algunas de las problemáticas documentadas en su acceso a las pruebas de detección y a la información que se provee en las instituciones de salud sobre el virus y discutimos las principales ausencias y omisiones desde la investigación académica, las políticas públicas y el nivel asociativo respecto al conocimiento e intervención en esta realidad que afecta a los pueblos indígenas. Finalmente, realizamos algunas recomendaciones de carácter aplicado subrayando la importancia de conocer el comportamiento de la epidemia en los pueblos indígenas, con datos de incidencia y prevalencia desagregados por etnicidad, y con el fin de ofrecer respuestas nacionales y locales adecuadas e integrales para la prevención, detección oportuna, atención y seguimiento oportuno de la infección que incluya a los pueblos indígenas, visibilizándolos como personas que también son afectadas por VIH. Para este abordaje temático, comenzamos con una revisión de los datos publicados sobre la prevalencia e incidencia epidemiológica de VIH entre algunos pueblos indígenas en Latinoamérica, ${ }^{1}$ deteniéndonos en la descripción de la situación actual en México, y finalizamos con una investigación etnográfica en Los Altos de Chiapas, México, que aborda el acceso a las pruebas de detección de VIH, la información sobre las características de la infección desde el modelo explicativo biomédico, y el acceso a condones de la población indígena en una clínica del sector público, y en un hospital del medio asociativo dirigido a esta población, ubicados en una ciudad de la región.

\section{Perfil sociodemográfico de los pueblos indígenas de Latinoamérica}

La mayoría de los pueblos originarios de América Latina comparten un perfil demográfico, es decir, son pobres — muchos de ellos sobreviven por debajo de la línea de la pobreza, alcanzando niveles alarmantes-

\footnotetext{
${ }^{1}$ Estos datos fueron obtenidos en el marco de una consultoría sobre el estado de la cuestión de VIH en los pueblos indígenas de Latinoamérica, realizada por los autores y financiada por Onusida y el Secretariado Internacional de Pueblos Indígenas ante el VIH/sida, la sexualidad y los derechos humanos.
} 
y mantenidos al margen de los beneficios del desarrollo económico. Por ello son más propensos a la marginación política y legal, a poseer bajos índices de alfabetización y educación, a tener menor acceso a las oportunidades económicas, a los servicios de salud, empleos y a los conocimientos biomédicos sobre la salud reproductiva y la salud sexual (Cepal, 2006).

En muchos de sus territorios se encuentran yacimientos petroleros, bosques, selvas, las principales presas hidroeléctricas, áreas protegidas y, también, los municipios con los más altos índices de marginación. Es importante señalar que gran parte de sus ecosistemas han sido destruidos gradualmente debido a la sobre explotación y saqueo indiscriminado de los recursos naturales, minerales - a cielo abierto- y pesqueros. A esto hay que agregar la modificación de sus vidas cotidianas por la presencia de colonos invasores, obras de infraestructura, la migración, los desplazamientos forzados, las guerras, el avance de las llamadas fronteras vivas, y su ausencia como tomadores de decisiones dentro de las supuestas propuestas de desarrollo (Ponce et al., 2016).

Pero más allá de ello, los pueblos indígenas están marcados por problemas estructurales caracterizados por la exclusión, la marginación, el racismo y el conflicto social, lo que se traduce en índices alarmantes de falta de servicios básicos: salud, educación, vivienda, electricidad, agua potable, red de drenaje, derecho y acceso a sus territorios, tasas de fecundidad más altas pero de educación más bajas, reducidos salarios y niveles de ingresos muy bajos, altos índices de analfabetismo - especialmente en las mujeres_-, deserción escolar, y perfiles epidemiológicos que se caracterizan por enfermedades propias de la pobreza, es decir, prevenibles (Cepal, 2006).

Su salud es precaria, en general la mortalidad materno-infantil es mayor que entre la población mestiza, la esperanza de vida es menor, sufren desnutrición crónica, tuberculosis, neumonía, malaria, dengue, Chagas, infecciones de transmisión sexual y el subregistro de mortalidad y morbilidad, incluido VIH y sida, es mucho mayor que en el resto de la población (Ponce et al., 2016).

Su relación con el sector salud presenta un doble reto, la factibilidad del acceso a los servicios y el tipo de atención recibida. El racismo 
institucional se manifiesta, entre otros, en la ausencia de traductores e intérpretes lingüísticos y culturales en la mayor parte de los centros de salud, así como en la falta de infraestructura, de medicamentos y personal cualificado en sus pueblos de residencia. El trato del personal de salud con frecuencia no es el adecuado y está cargado de concepciones negativas y culpabilizantes hacia las personas indígenas y sus problemas de salud y de atención. A su vez, y en parte como consecuencia de lo mencionado, estos pueblos mantienen cierta preferencia por los sistemas tradicionales de medicina y la automedicación y, por lo regular, recurren a los centros u hospitales cuando su salud está muy comprometida (Ponce et al., 2016).

Es importante destacar que la Organización Panamericana de la Salud (2003) y Cepal (2006) sostienen que la pobreza y la pertenencia a un pueblo originario están directamente relacionados. Para muestra dos ejemplos: 1) aproximadamente la mitad de la población indígena del continente vive en las ciudades. Los centros urbanos con mayor población debido a desplazamientos migratorios son la Ciudad de México, La Paz, Guatemala, y Lima, centros urbanos que poseen los mayores niveles de pobreza del Continente. 2) llama la atención que los y las indígenas que viven en áreas de reserva en Panamá y Costa Rica tienen niveles de analfabetismo y promedio escolar más bajo que aquellos que habitan en otro lugar.

\section{La epidemia de VIH en algunos pueblos indígenas de Latinoamérica}

Los escasos estudios desagregados por etnicidad sobre prevalencia epidemiológica existentes revelan datos desalentadores y alertan sobre la necesidad de conocer el comportamiento de la epidemia en esta población y abordar sus repercusiones en términos preventivos, de atención y seguimiento oportuno. Destacamos los casos de cinco países de Latinoamérica en los que se dispone de evidencia sobre la prevalencia de VIH entre ciertas poblaciones indígenas, ${ }^{2}$ todas ellas caracterizadas por altos niveles de pobreza, baja escolaridad, difícil o

\footnotetext{
${ }^{2}$ Para un panorama más amplio que incluye la situación en otros países de Latinoamérica ver: Ponce, Muñoz, Stival, Núñez,Bernal y Dector (2016); y Ponce, Muñoz y Stival (2017).
} 
poco acceso a los servicios de salud, alta movilidad con una ocupación laboral estacionaria de tipo internacional y/o del campo a la ciudad y expuestos al trabajo sexual. Poseen escaso conocimiento de VIH y sus formas de transmisión, poco acceso a pruebas de detección y al condón, inician su vida sexual tempranamente — sin protección-, acostumbran a tener múltiples parejas, gran parte de los hombres que suelen tener prácticas sexuales con otros hombres y con personas transgénero lo hacen sin el uso del condón, y muchas mujeres sufren de violencia física y sexual constante por parte de sus cónyuges y novios. En general, manifiestan altos índices de discriminación quienes están afectados/as por el virus (Ponce et al., 2016).

En Chile, según estimaciones presentadas al Ministerio de Salud por parte de la antropóloga Malva Marina Pedrero, "la población indígena Aymara del país, en los años 2010 y 2011, presentó una tasa de mortalidad por VIH de 9,1 por cada 100 mil habitantes", mientras que en la población no indígena fue de 2,9. Es decir, "los Aymara tienen hasta 3 veces más riesgo de morir por causas relacionadas al VIH”. En este sentido, datos de mortalidad por VIH reportados de 2004 a 2009 constatan que 3 de cada 10 muertes a causa de sida fueron de personas pertenecientes a este grupo indígena. Su riesgo de morir por esta infección de 2004 a 2006 era $160 \%$ más alto que el del resto de la población, y de 2007 a 2009 fue 170\% mayor (Pedrero Sanhueza, 2014).

En Ecuador existe una norma (Proyecto de Ley de Prevención y Protección Integral contra la Epidemia de VIH-SIDA, 2012) que obliga a desagregar los datos relativos a la etnicidad en el registro clínico y en los estadísticos, sin embargo nuestra experiencia investigativa en el país nos muestra que esto no se ha llevado a la práctica en la actualidad. Los únicos datos epidemiológicos desagregados por etnicidad de los que se dispone corresponden a un estudio realizado, entre 2009 y 2013, en la región de Morona Santiago por Family Care International. En Morona Santiago, situada en la Amazonía centro-sur, con 50\% de población indígena, se notificó un incremento de los casos de VIH de 680\% entre los años 2002 y 2013 . De los casos registrados, 50\% correspondía a población indígena de la nacionalidad shuar (Segura, 2015), mayoritaria en esa región. 
En el Plan Estratégico Multisectorial de VIH y sida. Prioridades 2007-2010 (Ministerio de Salud de Panamá, 2017), de Panamá, se reporta que la epidemia está concentrada en hombres que tienen sexo con otros hombres, trabajadoras/es sexuales y en las poblaciones indígenas de Ngäbe Emberá y Kuna, esta última con una prevalencia dos veces mayor que la estimada para población en general (Valverde, 2013).

El Plan Estratégico Nacional de Carácter Multisectorial para ITS, VIH y sida 2009-2014 (Ministerio de Salud de Panamá, 2009), coloca a los pueblos originarios entre los grupos vulnerables, destacando los kuna y los ngäbe buglé como prioridad media de intervención por considerar que hay falta de evidencias o son limitadas. Sin embargo, y contradictoriamente, el mismo documento seńala que la República de Panamá tiene una tasa acumulada de 138,8 por 100 mil habitantes con base en la población del año 2004, y los pueblos de Kuna Yala de 234,9, siendo la segunda localidad del país después de Colón con mayor tasa de VIH.

En el último Plan Estratégico Multisectorial de VIH/sida 2014-2019 (Ministerio de Salud de Panamá, 2014), nuevamente señala a la población indígena como un grupo vulnerable, ponderando que la tasa de seropositividad para el país es de 0,3\% y en Kuna Yala de 0,4\%, siendo la región sanitaria con mayor tasa.

En Perú, a pesar de la existencia desde 2010 de una norma que contempla indicar la pertenencia étnica en la ficha de registro clínico de las personas con diagnóstico de VIH no se cuenta con datos desagregados por etnicidad, sin embargo, existen algunos estudios e investigaciones que nos acercan a la problemática.

En el "Análisis de la situación epidemiológica del VIH y sida en el Perú 2013" se muestra un reporte epidemiológico donde se manifiesta que en 2004 se realizó un estudio de seroprevalencia de VIH y sífilis en la comunidad indígena amazónica Loreto, Chayahuita, obteniéndose una seroprevalencia de VIH en adultos de 7,5\% — 6 de 80—y de 6,3\% para sífilis (Zavaleta et al., 2004).

En los resultados de la Encuesta Nacional de Prevalencia de ITS y VIH de 2007 (PREVEN \& AMAZON, 2007), se menciona que existe alta prevalencia de $\mathrm{VIH}$ - mayor a $2 \%$ - entre varones de las ciudades 
de la selva: Puerto Maldonado y Yurimaguas, aunque no se define la pertenencia étnica.

En Venezuela, una pesquisa periodística (Vitti, 2015, 2016) sostiene que en 2011 el Instituto Venezolano de Investigaciones Científicas y el Instituto de Biomédica de la Universidad Central de Venezuela realizaron investigaciones en 26 comunidades warao del Delta del Orinoco encontrando la presencia del virus en $9,55 \%$ de los habitantes de 8 comunidades, lo cual representa una prevalencia altísima tomando en cuenta que en el país es de $0,56 \%$. La comunidad más afectada es Usid - 21,6\%-. Se reporta que dichas comunidades llevan conviviendo con el virus cerca de 15 años, que se ha encontrado con una cepa más agresiva que desarrolla los síntomas en menos de 5 años y que hay comunidades ya desaparecidas, arrasadas por sida, afectando principalmente a jóvenes de entre 15 y 24 años.

\section{El caso mexicano}

En México no existen datos en un registro epidemiológico sistematizado que tome en cuenta variables como la pertenencia a un grupo étnico o la lengua que nos permitiera conocer el impacto de la epidemia en los pueblos indígenas. No obstante, se han realizado algunas pesquisas que nos aproximan al conocimiento de la temática, las cuales revelan resultados nada alentadores.

Guillermo Núñez (2011) nos dice que en Sonora las localidades con población mayos y de indígenas migrantes presentan tasas muy altas de VIH, particularmente esta última tiene una tasa cuatro veces superior a la media estatal. En el estado de Guerrero, VIH es la tercera causa de muerte entre las mujeres indígenas, la quinta en los hombres indígenas, y la séptima entre las no indígenas (Freyermuth, 2016).

Algunas investigaciones (López, 2008; Suárez, 2009; Quintal y Vera, 2016) realizadas en pueblos indígenas concuerdan en señalar que dichas poblaciones no tienen un nivel satisfactorio de conocimientos sobre el virus, sus formas de transmisión, sus manifestaciones y modos de prevención; además de existir un alto nivel de discriminación para las personas que viven con VIH y una muy baja percepción del riesgo. Añaden que dichas poblaciones tampoco tienen acceso a condones ni 
pruebas de detección de VIH, y los hombres en escenarios migratorios ejercen prácticas de riesgo, por lo que al volver colocan a sus mujeres en una situación vulnerable ya que ellas se encuentran sin posibilidades para negociar el uso del condón.

La Comisión Nacional para el Desarrollo de los Pueblos Indios, en el año 2009 (Ponce, Núñez y Báez, 2009), conjuntamente con el Centro de Investigaciones y Estudios Superiores en Antropología Social, realizaron una consulta nacional a los pueblos indígenas en seis estados fronterizos del país -Quintana Roo, Tabasco, Chiapas, Chihuahua, Sonora, Nuevo León - con el fin de documentar, entre otros, el grado de información y conocimientos que sobre VIH tenían. Para ello aplicaron 2,259 encuestas, mediante cuestionario, con representatividad estatal, a habitantes de comunidades indígenas y a los que vivían en las ciudades, con muestreo por cuotas de edad y género.

Uno de los resultados sobresalientes de la consulta es la ineficiente labor de los servicios de salud, pues se constató que a $85 \%$ nunca se le había ofrecido la prueba de detección oportuna de VIH; 56\% afirmó no haber recibido pláticas sobre VIH o sida, porcentaje que coincide exactamente con aquellos que pertenecen al programa Oportunidades, y sólo $30 \%$ identifica con precisión que VIH es una Infección de Transmisión Sexual (ITS). En este contexto, un escaso 5\% respondió afirmativamente que el uso del condón era una medida de protección, mientras que la mitad de la muestra señaló que no le habían enseńado a usarlo.

Otra consecuencia relacionada con la falta de respuesta institucional a la problemática se refleja en la recurrencia al uso de mitos para explicar las vías de transmisión: más de 33\% considera que un mosquito puede transmitir el virus, $48 \%$ sostiene que es una infección originada fuera del entorno comunitario, dato que se encuentra asociado a $46 \%$ donde se responde que los y las migrantes que vuelven a su comunidad ya portan el virus. Cree $30 \%$ en la posibilidad de la transmisión a través del uso común de platos, cubiertos, y el sanitario. Otra creencia fuertemente arraigada es aquella que sostiene que lavarse la vagina después de una relación sexual evita la adquisición de VIH, 45\% de la muestra constata esta situación. 
Existen evidentes manifestaciones de estigma y discriminación en varios aspectos, 52\% de las y los entrevistados considera que las personas con VIH o sida no tienen derecho a procrear hijos; ni a tener relaciones sexuales, $43 \%$. Casi $33 \%$ asocia el virus con el trabajo sexual y las relaciones homoeróticas, así como $50 \%$ vincula el uso del condón con "la promiscuidad". Para concluir, debe destacarse que en $20 \%$ de las entrevistas se dice que las/os portadores del virus son expulsados de sus comunidades.

Aparte de que las instituciones del sector salud no están dando las respuestas necesarias a la problemática, las organizaciones de la sociedad civil han mostrado poco o nulo interés hacia el trabajo en las regiones indígenas y sus circuitos migratorios. Es un hecho lamentable que se niegue la especificidad indígena en el contingente migrante y su presencia en las grandes ciudades. También se registra que existen prácticas discriminatorias por parte del personal del sector salud y las propias organizaciones de la sociedad civil que inhiben sensiblemente el acceso de la población indígena a la atención oportuna, hecho que se suma a sus condiciones de marginación y vulnerabilidad económica, social y sexogenérica.

Hasta el momento sólo existe un trabajo científico documentado que ha incluido la prueba rápida para detección de anticuerpos antiVIH. Este proyecto se titula: "Sexualidad, migración y vulnerabilidad. Seroprevalencia por VIH en indígenas locales y migrantes en Sonora" (Bernal, 2015). Los hallazgos son de suma importancia dado que evidencian el impacto de la epidemia sobre los pueblos indígenas, al menos en Sonora. De acuerdo con este estudio de tipo multimétodo, se trabajó en 19 localidades indígenas que pertenecen a los municipios de Navojoa, Etchojoa y Huatabampo. El muestreo de las localidades fue aleatorio probabilístico y se incluyeron 530 participantes con los que se formaron dos grupos: no migrantes (380) y migrantes (150). Se aplicaron dos instrumentos de trabajo, una encuesta para la evaluación de riesgos, características sociodemográficas y movilidad poblacional, y se aplicaron cinco entrevistas semiestructuradas en las que se analizaron los temas: características sociodemográficas, acceso a servicios de salud y daños a la salud, movilidad poblacional, percepción de riesgos, 
sexualidad, conocimiento y dominio de herramientas de prevención y acceso previo a la prueba rápida. En dicho estudio se confirmó la presencia de VIH en cinco personas - tres hombres y dos mujeresrepresentando una prevalencia puntual de 0,94. Esta situación puede ser explicada de dos maneras: una, que la prevalencia de VIH en la población indígena en Sonora sea ocho veces mayor que la prevalencia estatal; otra, que esta última sea subestimada dada la carencia en las estrategias de detección oportuna.

La prevalencia de VIH en la población local sin antecedentes migratorios es 0,005 bajo las condiciones de vulnerabilidad estudiadas, mientras que la misma en la población migrante es 0,020 bajo condiciones de vulnerabilidad y migración, o sea, cuatro veces mayor en comparación con la población local no indígena Esta aseveración se apoya, además, en el hecho de que los migrantes presentan entre 3,1 y 8,3 veces más posibilidades de tener once o más parejas sexuales durante el proceso migratorio, en comparación con las personas sin tal antecedente.

Estos argumentos cuantitativos permiten afirmar la evidencia de que VIH es un problema de salud pública que afecta a los indígenas y sobre todo a los indígenas migrantes, dada la falta de estrategias dirigidas específicamente a la prevención del mismo y a las experiencias durante la movilización poblacional, sobre todo el acceso a drogas, la inseguridad laboral, la gestión de afecto o relaciones sexuales consensuadas y, en el caso de las mujeres, la violencia sexual.

En el proyecto también se identificaron tres personas indígenas, dos hombres y una mujer, con alguna condición clínica de sida — síndrome de desgaste y comorbilidades-, además ocurrió una defunción debida a complicaciones propias del virus, representando al menos para el estudio una tasa de decesos correspondiente a $25 \%$.

De ahí la importancia de crear espacios en los que se acerque el servicio de prevención y detección oportunas, tal es el caso de garantizar la prueba rápida al menos en las unidades médicas rurales, en las indígenas, y en hospitales. 


\section{Un estudio de caso en la población indígena de Los Altos de Chiapas, México}

El doctor Rubén Muñoz, coautor de este artículo, llevó a cabo una investigación en Los Altos de Chiapas, periodo 2011-2013, en el marco de una estancia postdoctoral realizada en el Centro de Investigaciones y Estudios Superiores en Antropología Social, CIESAS Sureste. ${ }^{3}$ La investigación se inscribió en la subdisciplina de la antropología médica y tuvo un carácter aplicado que buscó realizar propuestas para la mejora del acceso y apego al tratamiento antirretroviral de las personas indígenas con VIH, así como a la información en salud sexual y a las pruebas de VIH y condones en una ciudad de esta región. Las unidades de análisis fueron el Servicio de Atención Integral (SAI) a Personas con VIH-sida; el módulo de atención en salud sexual a jóvenes, de una clínica de la Secretaría de Salud, y dos consultorios de un hospital perteneciente a una asociación civil dirigido a población indígena. La investigación tuvo dos objetivos principales: por un lado, esclarecer las representaciones sociales de los médicos con respecto a las prácticas sexuales y preventivas de VIH, y a los modelos explicativos del proceso salud/enfermedad/atención de las y los usuarios indígenas, además de las prácticas clínicas que se podían derivar de dichas representaciones. Otra de las intenciones fue dilucidar algunos aspectos de la cultura organizacional de atención médica - como por ejemplo la existencia o no de traductores/intérpretes - que mediaban en el acceso a la prevención-atención en salud, así como en la calidad y especificidades de las mismas.

Los resultados relativos a la atención a usuarios de SAI se publicaron en dos artículos (Muñoz, 2014a, 2014b). Aquí presentamos y discutimos los resultados, hasta la fecha inéditos, que se obtuvieron en la clínica de la Secretaría de Salud y en el hospital de la sociedad civil dirigido a población indígena, respecto a: las implicaciones de una traducción e interpretación lingüística-cultural no profesional en la relación médico/paciente/institución, el trato discriminatorio por la condición de salud y la identidad étnica, el derecho a la confidencialidad,

\footnotetext{
${ }^{3}$ Financiada con una beca postdoctoral de la Agencia Española de Cooperación Internacional y Desarrollo del Ministerio de Asuntos Exteriores y de Cooperación español, MAEC-AECID.
} 
al acceso a los condones e información requerida, al consentimiento informado y a las consejerías pre-prueba de detección de VIH.

Si bien la salud sexual en población indígena, y concretamente la vulnerabilidad social ante VIH, ha sido abordada en la región por diversos autores (ver Freyermuth, 2007; Reartes, 2010), la atención médica relacionada con el estigma hacia la condición de salud VIH positiva, así como su detección, articulada con el racismo institucional, es un campo investigativo incipiente. En este sentido, Menéndez (2006) señala que en las últimas tres décadas en México no existen estudios ni intervenciones que traten de indagar sistemáticamente la presencia de aspectos racistas en la relación terapeuta/paciente/institución e intenten modificarla, pese a ser un componente de la misma. Los campos de la prevención, detección y atención médica de VIH ponen en evidencia, de una forma quizá más visible que en otros, las desigualdades sociales al reactualizar, a través del estigma y la discriminación vinculados con la forma de adquisición del virus (ver Parker y Aggleton, 2002), inequidades sexogenéricas, de clase social y étnicorraciales.

La investigación etnográfica estuvo basada en la teoría fundamentada (Glasser y Strauss, 1967), y las técnicas de obtención de datos empíricos fueron las siguientes: 29 entrevistas en profundidad a miembros del personal de salud y responsables de las clínicas mencionadas, expertos pertenecientes al ámbito académico y de las asociaciones civiles, A. C., en el tema de estudio; usuarios que acuden a los servicios estudiados o dejaron de hacerlo, con identidad étnica por autoadscripción mestiza e indígena, hombres y mujeres de 18 a 45 años y de ámbitos urbanos y rurales. Se realizó observación participante a través de visitas, a lo largo de dos ańos, a las instituciones de estudio y a algunas de sus actividades externas. Se utilizó la estrategia de los usuarios simulados capacitando a ocho participantes en cuestiones relativas a la discriminación y estigma en los cuidados de salud. Posteriormente se desarrolló un guión de observación e interacción, que los participantes produjeron en función de sus vivencias previas, y se conformaron dos grupos focales, uno al comienzo y otro al final de la experiencia. A su vez cumplimentaron un cuestionario con preguntas cerradas tras cada visita a las clínicas - de tres a seis visitas por usuario-. El perfil de los usuarios fue el de 
jóvenes entre 18 y 30 años, tseltales y tsotsiles, cuatro mujeres y cuatro hombres (ver Muñoz, 2014a).

\section{El módulo de atención a jóvenes en Clínica $S$ de la Secretaría de Salud}

Situado en un lateral de la Clínica $S$, incorporada al primer nivel de atención de la Secretaría de Salud en la ciudad, se puede acceder directamente desde el estacionamiento o bien atravesando la clínica por la puerta principal. Provee orientación en salud sexual a jóvenes de 12 a 18 ańos, considerados población abierta — no afiliada a seguros—, de forma gratuita, además de atención en ITS y talleres en el marco del programa Oportunidades, que tienen carácter de obligatorios. En ocasiones puntuales atienden patologías, sin embargo éstas las suelen derivar a los consultorios de medicina general de la Clínica.

En dicho módulo hay una "condonería", aunque no está disponible al encontrarse la caja en el interior de la consulta, ser necesario presentar una identificación personal y firmar un documento para obtener algún condón, lo cual representa una barrera para las y los entrevistados que acuden o desean ir a la consulta por ellos — una gran mayoría-, quienes ya de por sí mencionan "sentir vergüenza" al requerirlos. Por otro lado, supone el desperdicio de un mecanismo de vinculación, ya que los condones es lo más solicitado, junto con información sobre VIH que la institución provee.

Las y los jóvenes indígenas a los que se les preguntó mencionaron que prefieren obtener dicha información en Internet, al ser más cómodo y menos comprometedor para su anonimato, debido a la posibilidad de ser vistos por allegados. El siguiente testimonio da cuenta de algunos de los problemas que encontraron participantes indígenas al acudir a este módulo:

En la consulta estaba la doctora con otra persona. Me preguntaron el nombre, de dónde era y mi edad. Me dijeron que sólo atendían a personas entre 12 y 18 ańos; sin embargo, dijo la doctora a su acompañante: "Probablemente la enviaron aquí ya que no hay un lugar en su comunidad". 
Me dio una explicación rápida sobre los condones masculinos y femeninos y me dijo que si quería me podía aplicar un método que consistía en un tubo con hormonas en el brazo. No me habló de un análisis previo ni me dijo en qué consistía. Pregunté sobre el sida y me dijeron que ésa era una enfermedad de transmisión sexual y que no había problema conmigo. Yo mencioné que me preocupaba mi esposo, ya que le habían visto con muchas mujeres, y me dijeron [en la consulta] que tuviese cuidado y que si quería una prueba de VIH. Yo contesté que no, que sólo quería información, y me dijeron que la información no servía de nada si no tenía sida... pregunté que cómo era lo de la prueba y me contestaron que era un piquete rápido, un tubo pequeño. La médico me dijo que le acompañase para hacérmela... no me preguntó si estaba de acuerdo. Llegamos a una oficina, no era un laboratorio ni estaba en el módulo [de atención a jóvenes], con dos mesas de trabajo y una vitrina. De allí sacaron el tubo. Estaba un doctor. La médico le dijo a este señor que me iba a hacer una prueba de VIH. El doctor me preguntó que de dónde venía y que por qué sospechaba que tenía sida. Le conté lo de las mujeres y mi novio, y me preguntó [el doctor] si estaba segura. Contesté que no estaba segura pero que quería saber qué es el sida y qué síntomas se dan cuando se tiene. El doctor explicó que no es sida, primero es el VIH y que no tiene ninguna reacción, que sólo desgasta el cuerpo y después, cuando hay síntomas, se transforma en sida. Pregunté que cómo se podía saber si se tiene, y me dijeron que con gripe pues es fácil que se contagie... En la sala estaba la médico y tres mujeres más... Las otras enfermeras entraban y salían, pero una de ellas estaba muy atenta. Salió negativo y me dijo que no tenía. La doctora me preguntó que si tenía dudas... y yo dije que muchas. La doctora brincó a la mesa para escucharme y me asusté un poco [por la reacción]. Entonces yo pregunté por el embarazo, si tengo sida y me embarazo qué pasaría. Y la médico decía que sí se transmite siempre, el bebé se afectaría, y que no tendría que embarazarse en ese caso; pregunté qué pasaba si mi novio tiene sida. El doctor me dijo que tengo que prevenirme en ese caso y llevar condones. Pregunté que si al no tener hijos me quería embarazar de mi pareja y él tiene sida, ¿qué pasaría? Y las mujeres decían que ellas no se embarazarían, respondiendo por su cuenta y sin 
escuchar lo que yo decía. Me dieron condones y me hicieron firmar un papel para poner la fecha y mi nombre. Me sentí intimidada por la falta de información y de privacidad. No sentí confianza con las personas que me atendieron, no sabían cómo responder a las preguntas. Si hubiese sabido habría preguntado más cosas. La médico reconoció que no me había preguntado cuando ya estaba a punto de hacer el análisis. El médico le dijo [a la doctora] que firmase [yo] un papel de autorización de prueba rápida. No me explicaron si quería, pero cuando me daban el papel mencionó [la médico] que lo hacía porque ella [la paciente] quería. Cuando me dieron la información estaban todos en la consulta y, encima, daban sus ideas (paciente simulada, presentación en español, con ropa tradicional de Chamula, 28 años, 2012).

La experiencia relatada documenta la vulneración del respeto a la confidencialidad de la usuaria por parte del personal de salud, así como del derecho a la información adecuada y al consentimiento informado sobre el método anticonceptivo basado en hormonas, las características del VIH y la prueba de detección —el consentimiento se firma después de la prueba-. En cuanto al respeto a la confidencialidad, en ningún momento se toman medidas para que ésta sea salvaguardada y así lo perciba la usuaria, permitiéndose la entrada a la consulta y la opinión sobre su caso, durante la misma, de aquellos actores que por allí transitaban. Otra cuestión relevante en la relación médico-paciente-institución es la representación de la médico con respecto a la sexualidad de la usuaria. Como hemos discutido en otros documentos (Muñoz, 2014b) los médicos, en este contexto, conciben la sexualidad de la mujer, más aun si es indígena y tiene pareja, ligada a la monogamia, vista esta última como un factor de protección frente a VIH: "Esto [VIH o sida] es una enfermedad de transmisión sexual, no hay problema contigo", menciona la doctora ante la solicitud de información por parte de la usuaria. Al relatar la conducta de riesgo del marido cambia su actitud [la médico] ofreciéndole la prueba rápida de detección de VIH. 


\section{Respuestas desde la sociedad civil: \\ el Hospital $\mathrm{D}$ dirigido a población indígena}

El hospital D atiende a población indígena de diferentes regiones de Chiapas y fue creado por una asociación civil con médicos que realizan sus pasantías provenientes de dos universidades del norte del país, al igual que su fundador. El principio fundacional del hospital que justifica esta característica es tratar de incluir a las personas que sufren discriminación por su origen étnico en las instituciones públicas de salud, entendiendo que "Los médicos de fuera le dan un mejor trato a los indígenas que los de esta ciudad" (médico generalista, P., 2011), además de recibir de la Asociación Civil una capacitación específica en atención sensible a la diversidad cultural con este objetivo. El número de pacientes atendidos anualmente comprende entre 20,000 y 25,000. El precio de cada consulta es de 30 pesos (información obtenida en entrevista a director médico, 2012).

La clínica tiene una estructura semejante a la de una casa de campo con un jardín a la entrada. La disposición del espacio trata de, según el relato de los miembros de la organización, propiciar que "Los pacientes se sientan a gusto, como en sus comunidades, pudiendo comer y descansar antes de entrar en la consulta" (director médico, 2012).

La cruz simboliza la adscripción religiosa de la A.C. No existen traductores lingüísticos/culturales profesionales. La traducción formal la llevan a cabo dos enfermeros y el psicólogo, hablantes de tsotsil y tseltal, además de otros trabajadores del hospital que puedan ser solicitados en caso de necesidad.

Los pacientes simulados que participaron en la investigación percibieron el trato en la recepción como bueno. Así como el de los médicos, quienes se dirigieron a ellos, según su apreciación, con afabilidad y respetuosamente, además de conocer a los pacientes habituales por sus nombres.

Una vez estaba con una paciente y de repente empieza a llorar. Y le digo a la hija, porque la hija es la que hablaba español, “¿y qué le pasa a tu mamá?”, es que dice que está contenta porque nunca la habían tratado tan bien. Yo no sentí que fuera tan amable en ese momento, hasta para 
eso estaba apurado, y pensé, pues, cómo las tratarán en otro lugar. Ya me ha pasado en otras ocasiones de que no es que mi familiar está muy a gusto porque lo tratan muy bien aquí, y yo no siento que es así tan dulce, o no sé, pero a lo mejor en otros lugares realmente les hablan de mala manera (médico generalista, 2011).

Dos son las problemáticas en la atención que se han podido documentar en este hospital, por una parte, los efectos de la falta de preparación de algunos médicos sobre prevención/atención de VIH y sida, los estereotipos acerca de la sexualidad de las mujeres indígenas y la diversidad sexogenérica. Por otra, la dificultad para llevar a cabo una traducción/interpretación efectiva cuando el o la usuaria no habla espańol, y los problemas que de ello se derivan en términos de una atención adecuada.

Empecé con mi pregunta de qué era el sida porque no entiendo bien el concepto de sida, y después ella me dijo... “qué quieres saber?”. Y le pregunté sobre las diferentes enfermedades de transmisión sexual. Sí, se sorprendió un poco y me dijo, tenía una laptop, "Espérame, voy a buscar información".

Y sacó su laptop. Y empezaba a buscar y saca un papelito y empieza a escribir ... Le pregunté cuáles eran los métodos anticonceptivos, y luego ella saca otro papelito y me dijo: “éste es el método...”. Mi primo me comentó que [mi novio] tenía relaciones con hombres, le dije eso. Allí cambió la actitud de la doctora, porque me dijo: "Los hombres [homosexuales] —no me acuerdo bien el porcentaje o uno de cada diez hombres o uno de cada cinco hombres- son contagiados... entonces, puedes estar infectada". Justo en ese momento reaccionó, como que tuvo miedo o algo así, bueno, ésa era la actitud facial, el terror que ella tenía, y dijo: "pero, ¿cómo te sientes?". Y se me quedaba viendo así como ¿qué pasa?, parecía que a ella jamás le habían preguntado sobre esa enfermedad y entonces la reacción de la doctora fue algo rara ... “¿Cómo me había sentido?”, que si tenía algún síntoma, y yo le decía que no, que todo bien, y ella me dice: "debes de ir hacerte pruebas, una prueba del VIH”, y me pidió nuevamente mis datos para que yo 
pasara en el laboratorio para que me hagan mi análisis. Proporcioné mis datos y, en fin, estuve en el laboratorio y me dijeron que el médico sale a las dos, algo así, ya no me puede atender; me dijo: "Te va a atender mañana”, y le fui avisar a la doctora que no me atendieron porque el doctor ya se fue. "Tienes que venir mańana". "No voy a poder, pero vengo el jueves". "Tienes que venir el jueves, porque tienes que hacerte ese análisis y también si es posible tráete a tu novio para que se venga hacer el análisis". "Claro, sí vamos a venir el jueves. (Al momento de salir, la saludé.) Nos vemos, doctora, y gracias". Ella me quitó la mano rápido ... Sentí que me discriminó porque pensó que yo tenía el VIH (usuaria simulada, presentación en español, ropa tradicional de Chamula, 19 años, 2012).

El relato evidencia la falta de formación en ITS de la doctora y de sensibilización en relación con el estigma hacia VIH y sida, llegando a tener actitudes que son percibidas como discriminatorias. Por otra parte, en una situación en la que hay elementos para pensar que la usuaria puede tener VIH el personal de salud no debería dejarla ir cuando está dispuesta a hacerse la prueba de detección, y no es seguro que vaya a regresar otro día.

Los aspectos problemáticos del siguiente relato, en el que la usuaria simulada se presentó hablando sólo en tsotsil y actuando como si no comprendiese el español, se refieren a la traducción/interpretación lingüística y cultural.

Cuando me empezó a preguntar el doctor por mi nombre, dónde vivía...La traducción era pésima...Todo lo que decía el doctor lo traducía de otra forma el traductor. Por ejemplo, si le preguntaba si era casada decía otra cosa. La traducción era como una mezcla del tsotsil, traducido al espańol de una forma literal, con el tseltal...; una mezcla rara. Después, cuando le pregunté al doctor si el sida tiene cura, el enfermero no contestó, y le volví a preguntar... me contestó que sí tenía cura. Muchas de las preguntas que yo hacía no se las hacía al doctor, él las respondía [el enfermero] por su propia cuenta. Me dieron condones y le pregunté al enfermero: “¿Esto cómo 
se usa?". "Si tu esposo ha estado en USA, él sabe...”. "Pero, ¿cómo lo voy a usar?". "Esto es de tu esposo". Le pregunté por los óvulos para infecciones vaginales y el doctor explicó muy bien cómo se usan, pero el enfermero no sabe explicar la parte íntima. No le pregunta al doctor porque piensa que sabe y así lo quería demostrar. El enfermero sentía vergüenza y timidez por lo que preguntaba... había movimientos corporales que demostraban nerviosismo de su parte y le daba muchas vueltas a la hora de traducirle al doctor. Cuando entré a consultarlo, le pregunté al doctor, "Quería preguntar sobre el sida, porque mi esposo llegó enfermo de USA". Y el enfermero, antes de traducir, me preguntó: “¿Pero tú sabes que tienes sida?”. "No, pero quiero saber qué es esa enfermedad porque me han dicho que es muy peligrosa". Y el enfermero dice, no le pregunta al doctor: "Es que no podemos saber si tienes sida así nada más, te tienen que quitar sangre". "Sí, pero quiero saber qué es eso...”. Entonces, después de que yo le insistí, ya le preguntó al doctor. Entonces, el doctor respondió de manera muy sencilla qué era, para que pudiera entenderlo. Después de tres veces de haberle insistido, el enfermero tradujo "condón” como condón. Yo le pregunté: “pero, ¿qué es condón?, ¿qué es preservativo?”. Y me dijo el enfermero: "Es algo que se pone el hombre”. “¿Qué es preservativo?”. Y le preguntó al doctor que yo no sabía qué era y allí se quedó... el enfermero dijo que me tenía que hacer una prueba.

El médico me preguntó sobre mi marido, el tiempo que llevaba, etc. Esta parte sí estuvo bien traducida... les dije que "Regresó de USA muy flaco, se enfermaba a menudo, se cansaba al trabajar...", y el doctor dijo que podía tener sida y me propuso que me hiciera la prueba, que no me preocupara. Me hicieron dos tipos de prueba: hepatitis y el sida. En el laboratorio nadie habla tsotsil. Pregunté cómo iba a ser el proceso de sacar sangre... el enfermero decía: "No va a doler, solamente te van a sacar sangre”. No me dijeron en qué consistía la prueba. “¿Cuánto va a costar la prueba, porque no sé si me va a alcanzar el dinero?”. Y ya es cuando me dijeron, 150. De cómo iba a ser no me dijeron. Era como si el enfermero fuese el doctor. En el laboratorio había una señora que no hablaba tsotsil. Me dijo que esperase a las 12 [1 hora] para recoger los resultados, y yo le pregunté 
“¿cómo le hacía?, ¿llamaba a la puerta....”. Ella me dijo que no me entendía nada y salió a llamar al jardinero para que tradujese. La mujer decía: "dile a la muchacha que venga a las doce, en hora nueva, a recoger el resultado". Y el jardinero traducía que fuese en una hora, en hora vieja, por el resultado [hora vieja es la de la comunidad, la una de la tade; y nueva es la de la ciudad, las doce]. Estaba fuera esperando, me llamaron, tenía que regresar con el doctor que me atendió. Otra vez con el enfermero, le pregunté que qué íbamos a hacer con esto, y me dijo que esperase al doctor.

Los resultados me los dio directamente la [encargada] química, y el doctor salió y le di los resultados y mostró un rostro de satisfacción y dijo [en el pasillo] que no tenía sida. Me dijeron que mejor que trajera a mi marido pues hay tres cosas que hacen enflaquecer a las personas: sida, diabetes y cáncer. El doctor me preguntó que si tenía algunos síntomas en mi cuerpo, y el traductor traducía con cierta pena. Yo respondí que sentía comezón. "Es alguna infección y te vamos a recetar". No me hicieron exploración... Me preguntaron si tenía flujos, respondí lo que decía el médico porque no se le entendía al enfermero al traducir "flujo". Recomendaría que fuesen al hospital, pero si el paciente no habla español que fuese acompañado. Esto me pasó siempre que he ido con mi mamá [a centros de salud], no hablan [los enfermeros bilingües] nunca en nuestro idioma. Me imagino que por un lado quieren que hablemos español, pero por otro creo que es por presunción: hablan español, trabajan en un lugar de la ciudad, casi nadie trabaja por allí... y él es superior a los pacientes. Los médicos me parece que hacen un esfuerzo para dar un buen trato, algunas de las cosas que explicaba yo en tsotsil lo entendía el doctor (usuaria simulada, presentación en tsotsil, ropa tradicional de Chamula, 28 años, 2012).

Los problemas en la traducción/interpretación que se reflejan en este relato tienen que ver con su ejercicio no profesional, así como con el género y la trayectoria sociocultural del enfermero y la usuaria. La traducción en un contexto clínico implica tener una formación, teórica y metodológica, que permite la práctica de su correcto ejercicio y la precaución frente a las posibles derivas que pueda conllevar. 
Dichos problemas guardan relación con el contenido lingüístico de la comunicación, pero también con su inscripción, significados e interpretación en uno o varios universos culturales de enunciación y referencia, así como con las trayectorias socioculturales de los traductores y la incidencia de sus supuestos implícitos (ver Muñoz, 2013). En lo relativo al conocimiento de la lengua desde la que se va a traducir, el enfermero no es hablante de tsotsil. Por otra parte, ante ciertas palabras específicas no existen términos equivalentes entre una y otra lengua.

Pero esto me ha tocado, he experimentado eso de como que hay una confusión, es problema urinario, pero ellos [los pacientes] no lo expresan bien, no te lo mencionan tal cual es la cavidad vaginal... se me dificulta mucho porque traduciendo no tengo nombres en dialecto [idiomas tsotsil y tseltal] de los métodos anticonceptivos, no tengo en dialecto la parte genital de la mujer, no, no existen en tsotsil o tseltal (psicólogo que ejerce a su vez de traductor, 2011).

Otro problema en el ejercicio de la traducción es que muchos médicos (ver Muñoz, 2013) consideran que se ralentiza la consulta - lo cual no sólo sucede, si no que es necesario para una buena traducción-y potencialmente implica una pérdida de tiempo:

Muchos saben hablar algo de español, te pueden entender y, si no, vienen acompañados de algún familiar o un amigo que hable español. En dado caso que no tuvieran a nadie que hablara español, pues está José [el jardinero] o están los enfermeros Pablo y David, que conocen los dialectos tsotsil, tseltal y español, entonces nos ayudan a traducir, pero igual es más tardada la consulta (médico generalista, 2011).

Esto influye con frecuencia en un sentimiento de premura, por parte del traductor, que lleve a obviar o traducir superficialmente aspectos importantes de la información que médico y paciente intercambian. Otra cuestión problemática es el solapamiento entre la función del, en este caso, enfermero y sus roles en tanto que enfermero y traductor 
al mismo tiempo. A lo anterior se suma, como menciona la usuaria simulada y se pudo registrar en otros testimonios, la incidencia metodológicamente no controlada de su trayectoria sociocultural y profesional en su práctica como traductor con usuarios de origen étnico indígena, a través de la atribución de funciones que no le corresponden y de una selección de información e interacciones comunicativas, en la traducción, no basada en criterios de eficacia clínica y en una atención respetuosa con los derechos humanos y la diversidad cultural: "Quiere que hablemos español, pero por otro [lado] creo que es por presunción: habla español, trabaja en un lugar de la ciudad, casi nadie [indígena] trabaja por allí...y [cree] que él es superior a los pacientes" (usuaria simulada, 28 años, 2012).

Éste es el caso cuando no le pregunta al médico y da respuestas por su cuenta, algunas de las cuales son erróneas, como sucede al contestar a la paciente que "el sida tiene cura". Los supuestos morales del traductor respecto al género de la paciente y su poca familiaridad con el abordaje del VIH se expresan, en ausencia de mecanismos de vigilancia metodológica y sensibilización en el desempeño profesional, en la negación de la información sobre el uso del condón al considerar que no es un asunto de una mujer: "Cuando me dieron los condones le pregunté al enfermero '¡esto cómo se usa...?', 'si tu esposo ha estado en USA, él sabe...' 'Pero, ¿cómo lo voy a usar?'. 'Esto es de tu esposo...””.

Por otro lado, un factor relevante, relativo al género de la usuaria y del enfermero con adscripciones étnicas similares, es la timidez percibida por ella, quien siente que está comprometiendo al enfermero al hacerle las preguntas, lo cual condiciona su demanda de información.

La privacidad de la usuaria constituye otro aspecto problemático. El médico consulta los resultados de la prueba de VIH en el pasillo de la clínica y los anuncia abiertamente. De igual forma le sucedió a otra usuaria simulada, de 24 ańos y vestida con su traje de Chamula, que preguntaba por el Papanicolau. Le hicieron esperar en la recepción a que llegase una enfermera. Finalmente, tras una hora de espera, llegó una médico y la atendió delante de los usuarios que hacían fila para la consulta: "Los pacientes se me quedaban viendo. Me pareció que se me quedaban viendo y riendo al preguntar esto" (usuaria simulada, 24 años, 2012). 
Esto evidencia algunos riesgos de hacer de la necesidad virtud y justificar, en la urgencia del aquí y ahora, una información o traducción sin que el personal de salud y la institución calibren las posibles consecuencias que puede tener el modo y el lugar donde se ponen en práctica. Especialmente cuando se trata de problemas de salud altamente estigmatizados en la sociedad actual.

En los dos casos analizados, al igual que sucede en SAI, en el que a su vez se desarrolló la investigación (Muñoz, 2014b) en el contexto de Los Altos de Chiapas, la cultura organizacional de atención médica, articulada a las representaciones y prácticas de sus profesionales, no contempla una atención sensible a la diversidad cultural y respetuosa con los derechos humanos, ejerciendo diversas formas de violencia institucional, aunadas a las existentes en la sociedad, por la condición étnica y genérica de los usuarios.

\section{A manera de inconclusión}

El análisis epidemiológico de VIH en México, así como en otros países de Latinoamérica, resulta poco útil cuando se requiere conocer el impacto de la epidemia en los pueblos indígenas. Esto se explica debido a que las cifras no se encuentran desagregadas por pertenencia étnica y, en general, porque dicho análisis se reduce a clasificar los casos de VIH o sida de acuerdo con factores de riesgo, vías de transmisión, según sexo, edad, ocupación, y finalmente su distribución por municipio y localidad de residencia. La etnicidad y el racismo como determinante social de la salud, los antecedentes migratorios, las rutas de movilización poblacional, la disidencia amorosa y sexual, y la homofobia y transfobia, así como otros determinantes consecuencia de procesos estructurales e ideológicos, no figuran en el análisis de la epidemia. Al reduccionismo del método epidemiológico, con clasificaciones acotadas a una perspectiva biomédica e individualista y estereotipadas a grupos denominados de riesgo, se han articulado las ideas preexistentes sobre la sexualidad de los pueblos indígenas en México en las que no existe la disidencia sexual, en un marco explicativo dominante que asocia VIH con homosexualidad. $\mathrm{Y}$ sus prácticas sexuales se conciben desde las sociedad mayoritaria como ancladas a una "sexualidad natural" (Bernal, 2015); esto es, 
autocontenidas en los grupos o comunidades, monógamas, ceñidas al mandato de la reproducción y acordes con la heteronormatividad.

Si los estereotipos culturales basados en la hipersexualización operan desde comienzos de la epidemia, a partir de una perspectiva centrada en lo que fueron llamados grupos de riesgo, como un eje ideológico que culpabilizaba del origen y dispersión de la misma, recordemos el uso discriminador de la vía sexual en el denominado Club de las $4 \mathrm{H}$ -hemofílicos, homosexuales, haitianos y heroinómanos- en Estados Unidos (ver Farmer, 1992; Comarof, 2007), en este caso la asexualización a través de la concepción eufemística de una "sexualidad natural", heredada de la evangelización durante la colonización de América, borra del mapa los efectos del impacto real de la epidemia en la población indígena. Lo cual se traduce en una efectiva reactualización del continuum histórico que pretende abocarlos a la invisibilización.

Así tenemos que en buen parte de Latinoamérica no encontramos ni cifras ni datos sobre el impacto de VIH en los pueblos indígenas - ya sea que vivan en zonas rurales o urbanas-, sin que ello cause extrañeza a gobiernos, programas y organismos internacionales, investigadores, servidores públicos del sector salud y, muchas veces, ni a las organizaciones de la sociedad civil que trabajan el tema, partiendo de la suposición de que la prevalencia es muy baja y que ya están cubiertas sus necesidades con las políticas de salud de carácter universal (Núñez y Ponce, 2015). El encuentro entre la alta estigmatización social existente en la actualidad respecto a VIH y el enfoque epidemiológico basado en los llamados "grupos de riesgo" opera a su vez como un pretexto, desde numerosas tomadoras/es de decisiones, académicos/as y miembros de la sociedad civil, a la hora de decidir no visibilizar su impacto en colectivos históricamente marginados, esto es, hay que "evitar" ahondar en la estigmatización de colectivos que ya están estigmatizados (Núñez y Ponce, 2015).

Frente a esta situación, que no es nueva y se remonta al origen de la epidemia, los colectivos sociales han desplegado respuestas diversas para impulsar medidas de prevención-atención y seguimiento oportuno respecto a este problema de salud a nivel nacional o internacional, mismas que han sido fruto de posibilidades de agenciamiento 
distribuidas desigualmente a nivel individual y colectivo. En este particular, la historia, las desigualdades y las necesidades específicas de la población indígena respecto al impacto de la epidemia de VIH han sido agendadas, de forma minoritaria, desde hace una década en algunos contextos puntuales de Latinoamérica, con un escaso correlato en la toma de decisiones del sector salud (Ponce, Muñoz y Stival, 2017).

Como hemos visto, en algunos países de la región han comenzado a realizarse esfuerzos para desagregar la prevalencia e incidencia por etnicidad con diversos alcances en dicho ejercicio, sin embargo en su mayoría constituyen una mera declaración de intenciones sin efectos empíricos en el registro. En México son inexistentes las aproximaciones desde las políticas públicas en salud para conocer el impacto de la epidemia y el proceso salud/enfermedad/atención-prevención en este sector poblacional. El panorama en la investigación académica es análogo, siendo recientes los escasos estudios realizados, con un carácter focalizado, sobre prevalencia e incidencia epidemiológica y existiendo una mayor disponibilidad de trabajos sobre prevención y vulnerabilidad social al VIH de tipo cualitativo. No obstante, si bien la falta de datos epidemiológicos dificulta gran parte de estas investigaciones al encontrar limitaciones en la justificación de su objeto de estudio desde los datos "duros", sus hallazgos son de gran riqueza analítica y descriptiva y suponen aportaciones teóricas y aplicadas que desafortunadamente no son, por el momento, aprovechadas por las políticas públicas para la generación de estrategias de actuación por parte de las instituciones de salud y de la sociedad civil.

El estudio de caso realizado en Los Altos de Chiapas evidencia que algunas de las características de la cultura organizacional de atención y de las representaciones sociales y prácticas de los profesionales de la salud, respecto a la etnicidad y el género del usuario, constituyen patrones estructurales que se encuentran presentes tanto en el nivel institucional público como en el ámbito asociativo. Dos ejemplos de ello son la concepción sobre la sexualidad de las mujeres indígenas y su incidencia en la provisión de condones e información sobre VIH; y las repercusiones, en forma de una atención respetuosa con los derechos 
humanos, culturalmente pertinente y eficaz, de la inexistencia de traductores e intérpretes lingüísticos y culturales profesionales.

Otro aspecto significativo que impacta en la relación médico/paciente/institución en forma de atención inadecuada y discriminatoria, en el hospital dirigido a población indígena es el carácter fortuito e inesperado que tiene para algunos médicos la posibilidad de abordar un escenario en el que la detección de VIH sea una de las demandas de un usuario del servicio. Gran parte de las desigualdades aquí documentadas que se reproducen desde la configuración cultural de las instituciones de salud a las que acuden los miembros de esta población ocurren tanto a nivel de la prevención como de la atención a personas indígenas con VIH en el contexto de Los Altos de Chiapas (ver Muñoz, 2014a, 2014b). Aspectos como la ausencia de traductores e intérpretes profesionales, y algunas de sus repercusiones en las tentativas de acceso a los servicios de prevención-atención de $\mathrm{VIH}$, tienen un correlato a nivel nacional y regional en diversos estudios publicados en Latinoamérica (Muñoz, Ponce y Stival, 2017).

La falta de reconocimiento del impacto de la epidemia en las poblaciones indígenas en México implica que no sean sujetas de derecho y que carezcan de estrategias preventivas, de atención, seguimiento oportuno y defensoría de los derechos humanos, que tomen en cuenta su especificidad sociocultural en contextos que se caracterizan por prácticas racistas y discriminatorias. Es importante resaltar las modalidades en las que el racismo invisibiliza la desigualdad social, negando la etnicidad como categoría de análisis de la realidad, y cómo en esta situación ser indígena, mujer, disidente amoroso y sexual, pobre, marginado y migrante expone a determinantes sociales, genéricos y culturales que se traducen en una vulnerabilidad diferencial a la adquisición de VIH. Es decir, la condición étnicorracial es un factor de vulnerabilidad en sí misma en la medida en que se articula con otros elementos estructurales tales como la pobreza, la migración, la falta de acceso a servicios educativos y de salud de calidad, entre otros.

Lo étnico también determina una vulnerabilidad adicional en los hombres que tienen relaciones sexuales con otros hombres, no sólo 
por tratarse de una población con un[a] alta prevalencia, sino también porque la formas de discriminación, estigma y racismo que se generan en los procesos migratorios condicionan conductas sexuales de riesgo (Núñez Noriega, 2008).

Coincidimos con el autor cuando plantea que:

... conocer y empezar a nombrar estas realidades, nos permitirá elaborar estrategias de prevención y atención, silenciarlas es condenar a mucha gente a una situación de vulnerabilidad al VIH, que se agrega a la falta de acceso a los servicios públicos de salud y educativos de calidad para la prevención y atención, así como a las condiciones económicas justas que les permitan vivir sin hambre, sin inseguridad alimentaria, sin la negación de su lengua y su cultura, sin pobreza y sin racismo (2008).

En este sentido, los autores proponemos algunas pautas a seguir con la finalidad de promover una respuesta social e institucional organizada ante VIH, enfocada en la atención integral, con especial énfasis en el abordaje preventivo y de detección oportuna, a nivel comunitario e individual, en población indígena que vive en zonas rurales y urbanas.

a) Desagregar el análisis epidemiológico por condición étnica y analizar la movilidad poblacional indígena interna - intermunicipal e interestatal- e internacional y la producción de vulnerabilidad social a VIH durante la misma, garantizando el acceso a la información para la prevención y la detección oportuna de los no derechohabientes.

b) Crear espacios de capacitación continua para el personal de salud en los que se trabajen sus percepciones y creencias respecto a la salud sexual y a VIH en población indígena — muchas de ellas, discriminatorias-, y fomentar procesos y prácticas que garanticen el ejercicio pleno del derecho a la atención integral en salud, al acceso a las pruebas rápidas con consentimiento informado, a la información básica con pertinencia cultural en las lenguas maternas de las y los usuarios indígenas, y a la confidencialidad. 
c) Fomentar la participación ciudadana de las y los indígenas, incluyendo a migrantes y disidentes sexuales, entre otros, reconociendo y validando los saberes y recursos locales con que cuentan en sus comunidades e incentivar su participación en el diseño e implementación de estrategias de atención integral frente a la epidemia.

d) Capacitar a líderes comunitarios en prevención de VIH, estigma y discriminación. Ampliar el acceso a las intervenciones, incluyendo a los colectivos más jóvenes; es decir, implementar programas de educación sexual en niños y jóvenes indígenas.

\section{Bibliografía citada}

Bernal Méndez, Daniel, 2015, Sexualidad, migración y vulnerabilidad. Seroprevalencia por VIH en indigenas locales y migrantes en el sur de Sonora, Tesis de maestría, Universidad de Sonora, Sonora.

Cepal, 2006, "Pueblos indígenas y afrodescendientes de América Latina y el Caribe: información sociodemográfica para políticas y programas", Santiago de Chile.

Comaroff, Jean, 2007, "Beyond Bare Life: AIDS, (Bio)Politics, and the Neoliberal Order", Public Culture Winter, vol. 19, núm. 1, pp. 197-219.

Farmer, Paul, 1992, Haiti and the geography of blame: AIDS and accusation, University of California Press, Berkeley.

Freyermuth, Graciela, 2007, "Migración y enfermedades de transmisión sexual en Chamula, Chiapas. Un estudio exploratorio ( $1^{\text {ra. }}$ parte)", en Graciela Freyermuth, Sergio Meneses y Germán Martínez (coordinadores), El señuelo del Norte. Migración indigena contemporánea, San Cristóbal de Las Casas, Chiapas, Coespo, Fondo de Población de las Naciones Unidas, ACAS, Chiapas, pp. 61-98.

Freyermuth, Graciela, 2016, "Mortalidad en los pueblos indígenas desde los determinantes sociales y la violencia estructural", en Graciela Freyermuth (editora), El derecho a la protección a 
la salud de las mujeres indígenas en México, CIESAS, CNDH, México, pp. 36-64.

Glasser, Barney y Anselm Strauss, 1967, The Discovery of Grounded Theory, Aldine, Chicago.

López Falomir, Liliana, 2008, Locus de control, preocupación, actitudes y conocimientos sobre el VIH: Análisis comparativo entre adolescentes indigenas y mestizos mexicanos, Trabajo de investigación, Máster en psicología de la intervención social, Universidad de Granada, España.

Menéndez, Eduardo, 2006, "Interculturalidad, diferencias y antropología at home. Algunas cuestiones metodológicas", en Gerardo Fernández Juárez (coordinador), Salud e inteculturalidad en América Latina, Abya Yala, Quito, pp. 51-66.

Ministerio de Salud de Panamá, 2009, Plan estratégico nacional de carácter multisectorial para ITS, VIH y sida 2009-2014, Panamá.

Ministerio de Salud de Panamá, 2014, Plan Estratégico Multisectorial de VIH/sida 2014-2019, Panamá.

Ministerio de Salud de Panamá, 2017, "Plan Estratégico Multisectorial de VIH y sida. Prioridades 2007-2010”, disponible en http:// cies.edu.ni/cedoc/general/FIPALRVIH/Docs/Documentos\%20importantes/Planes\%20Nacionales/Panama.pdf

Muñoz, Rubén, 2013, "Mediación intercultural frente a la desigualdad en el acceso a las cuidados sanitarios institucionales. Algunas consideraciones sobre las praxis profesionales en Bélgica y España”, Migraciones, núm. 33, pp. 97-125.

Muñoz, Rubén, 2014a, "Cultura organizacional de cuidados médicos, violencia institucional y desadherencia al tratamiento antirretroviral de las personas indígenas que viven con VIH-Sida en Los Altos de Chiapas", Revista Liminar. Estudios Sociales y Humanisticos, vol. XII, núm. 2, pp. 46-66.

Muñoz, Rubén, 2014b, “Atención Médica, Adherencia Terapéutica al Tratamiento Antirretroviral y Discriminación. Algunas problemáticas en la atención a personas que viven con VIH-sida, desde una perspectiva antropológica”, Revista Pueblos y fronteras digital, vol. 9, núm. 17, pp. 95-115, Cimsur UNAM. 
Muñoz, Rubén, Patricia Ponce y Matías Stival, 2017, "VIH, culturas médicas y discriminaciones étnicas: el acceso al tratamiento antirretroviral y la atención médica de las poblaciones indígenas de Latinoamérica”, Actualizaciones en SIDA e Infectología, Fundación Huésped, núm. 94, abril.

Núñez Noriega, Guillermo, 2008, "Pueblos originarios y afrodescendientes, diversidad sexual y genérica y vulnerabilidad al VIH/sida”, Conferencia magistral en encuentro Pueblos Indios, originarios, afrodescendiente frente al VIH/sida, las Sexualidades y los Derechos Humanos, México.

Núñez Noriega, Guillermo, 2011, "VIH-SIDA y población indígena en Sonora: Una aproximación cuantitativa y cualitativa", en Patricia Ponce, Guillermo Núñez y Mariano Báez, Informe Final de la Consulta sobre VIH-SIDA y Pueblos Indigenas en Áreas Fronterizas, CDI, CIESAS, México.

Núñez Noriega, Guillermo y Patricia Ponce, 2015, "Pueblos indígenas: Sexualidad, Diversidad Sexual y Genérica”, Revista Facultad Nacional de Salud Pública Iniciativas por la salud pública, Cartilla, núm. 7, pp. 57-75, Universidad de Antioquia, Medellín, Colombia.

Organización Panamericana de la Salud, OPS, 2003, Promoción de la salud sexual y prevención del VIH/SIDA y de las ITS en los pueblos indigenas de las Américas, Abana-YalaKunarinaki, Washington.

Parker, Richard y Peter Aggleton, 2002, HIVIAIDS-Related Stigma and Discrimination: A Conceptual Framework and an Agenda for Action, Population Council, Washington.

Pedrero Sanhueza, Malva-Marina, 2014, Situación de Salud de la Población Aymara en la Región de Arica y Parinacota. Evidencias de inequidades étnicas en el norte de Chile, Seremi de Salud Arica y Parinacota, Chile.

Ponce, Patricia, Guillermo Núñez y Mariano Báez, 2009, Informe final de la consulta sobre VIH SIDA y pueblos indigenas en áreas fronterizas, CDI, México.

Ponce Patricia, Rubén Muñoz y Matías Stival, 2017, "Pueblos indígenas, VIH y políticas públicas en Latinoamérica”, Salud Colectiva, vol. 
13, núm. 3, Instituto de Salud Colectiva, Universidad Nacional de Lanús, Buenos Aires, Argentina.

Ponce, Patricia, Rubén Muñoz, Matías Stival, Guillermo Núñez, Daniel Bernal y Jess Dector, 2016, "Estado del Arte sobre VIH y Pueblos Indígenas en América Latina”, Informe final, Onusida Sipia.

PREVEN \& AMAZON, 2007, Proyecto PREVEN: Encuesta Nacional de Prevalencia en ITS y VIH en Población General 2007, Universidad Peruana Cayetano Heredia, Lima, Perú.

"Proyecto de Ley de Prevención y Protección Integral contra la Epidemia de VIH-Sida”, 26 de septiembre de 2012, disponible en http://2009-2013.observatoriolegislativo.ec/media/archivos_ leyes2/Ley_de_Prevencion_y_Proteccion_Integral_contra_la_ Epidemia_del_VIH-SIDA.pdf

Quintal López, Rocío y Ligia Vera, 2016, “Análisis de la vulnerabilidad social y género en la díada migración y el VIH/SIDA entre mujeres mayas de Yucatán", Revista Estudios de Cultura Maya, vol. 46, diciembre.

Reartes, Diana, 2010, "Movilidad territorial y construcción de vulnerabilidad frente a ITS/VIH/sida entre estudiantes indígenas de Chiapas", Miradas en movimiento, vol. 4, pp. 70-95.

Segura, Maritza, 2015, "VIH y mujeres indígenas en Morona Santiago. ¿Persiste el silencio de las políticas públicas?”, Ponencia en III Congreso Latinoamericano y Caribeño de Ciencias Sociales. Flacso, Ecuador.

Suárez Tepetla, Claudia, 2009, Conocimientos y opinión que tiene la población nahua de la región de Zongolica Veracruz sobre el VIHSida, Tesis de maestría, Universidad Veracruzana, Veracruz.

Valverde, Zelibeth, 2013, "Situación de Salud de Panamá, Ministerio de Salud de Panamá, Panamá.

Vitti, Minerva, 2015, "Una epidemia de sida está diezmando a los warao", ARMANDOINFO, disponible en http://www.armando. info/historias/series/6033=una-epidemia-de-sida-esta-diezmando-a-los-warao 
Vitti, Minerva, 2016, "Pueblo indígena venezolano muere de Sida", Aristegui Noticias, disponible en http://www.elespectador.com/ noticias/elmundo/el-pueblo-indigena-venezolano-muere-desida-articulo-615674

Zavaleta, Carol, Connie Fernández, Kelika Konda, Yadira Valderrama, Sten Vermund y Eduardo Gotuzzo, 2004, "Short Report: High Prevalence of HIV and Syphilis in a remote native community of the Peruvian Amazon", The American Journal of Tropical Medicine and Hygiene, vol. 76, núm. 4, pp. 703-705. 